\title{
Knowledge and attitude among dental practitioners regarding the use of fluoride toothpaste for children
}

\author{
Aswathy Raju B ${ }^{1 *}$, Sageena George ${ }^{2}$, Anandaraj $S^{3}$, Veronica Rose Puthenpurackal ${ }^{4}$, Teena Haneef ${ }^{5}$ \\ ${ }^{1,4}$ Post Graduate Student, ${ }^{2}$ Professor and HOD, ${ }^{3}$ Professor, ${ }^{5}$ Senior Lecturer, Dept. of Pedodontics and Preventive Dentistry, \\ PMS College of Dental Science and Research, Thiruvananthapuram, Kerala, India
}

\section{Corresponding Author: Aswathy Raju B}

Email: draswathyrajub@gmail.com

\begin{abstract}
Aim: To evaluate the knowledge and attitude among dental practitioners in Kerala regarding the use of fluoride toothpastes for children.

Materials and Methods: A cross sectional descriptive, questionnaire based online survey was conducted among 300 dental practitioners in Kerala. A Self-administered, structured online questionnaire was send to them for the assessment of their knowledge and attitude regarding the use of fluoride toothpastes in children and the data was analyzed using SPSS 18 software.

Results: Among the study subjects, $40 \%$ of the respondents considered that it is very important to brush child's teeth with fluoride toothpaste. Whereas $66 \%$ of them knew that $1000 \mathrm{ppm}$ fluoride should be present in toothpaste for getting its benefit. $70 \%$ of the respondents recommended Kid's fluoride toothpastefor childrenand about $20.3 \%$ of them think kid's toothpaste contains $1000 \mathrm{ppm}$ fluoride. Only $18 \%$ of them recommended regular fluoride toothpaste for children. $60.7 \%$ of the respondents knew about the symptoms seen when high amounts of fluoridated toothpaste were ingested. $52.3 \%$ knew how to manage a child who had ingested high amounts of fluoride toothpaste and $64.7 \%$ knew how to reduce the intake of toothpaste by children. $66 \%$ of the respondents suggested twice daily brushing with fluoride toothpaste and $55 \%$ of them suggested pea sized toothpaste for children below 3 years.
\end{abstract}

Conclusion: Dental practitioners had less knowledge and attitude regarding the use of fluoridated toothpastes for children.

Keywords: Attitude, Knowledge, Fluoride Toothpaste, Dental practitioner.

\section{Introduction}

Dental caries can begin early in life and the main etiology behind are frequent intake of sugars, improper feeding and lack of oral hygiene measures. Children suffering from caries as infants \& toddlers have a greater probability of subsequent caries in both primary \& permanent dentition, so in order to prevent this, dental practitioners have a key role in promoting preventive measures against dental caries.

Among the various caries preventive strategies used, fluoride therapy has been the most effective method. During the last few years, there has been substantial decrease in caries and increased incidence of fluorosis and this has lead to greater attention and importance of topical fluoride therapy. Featherstone et al 1988 stated that the most important anti-caries effect of fluoride is considered to result from its action on tooth or plaque interface through promotion of remineralization of early caries \& reducing enamel solubility ${ }^{1}$. Topical fluoride therapy can be given either by the use of fluoridated toothpastes, mouthrinses, gels and varnishes. Use of fluoride toothpaste has been the most recommended method to control and prevent dental caries. The lack of knowledge and awareness among dental practitioners regarding the use of fluoride toothpaste for younger children has lead to inconsistent and conflicting recommendations to the caregivers of children thus limiting its efficacy. Hence the goal of this study was to evaluate the knowledge and attitude among dental practitioners regarding the use of fluoridated toothpaste for children.

\section{Materials and Methods}

A web based cross-sectional survey was conducted among licensed dental practitioners in Kerala. A simple random sampling was done and a sample size of 300 dental practitioners was decided. The survey ensured confidentiality as no personal information on the participants' identity was disclosed. The questionnaire was prepared by the researcher and consisted of 16 questions, which was organized into two parts: the first three questions elicited information on the demographic attributes of dental practitioner including age, gender, and qualification. The rest 13 close ended questions assessed the participant's knowledge and attitude regarding the use of fluoride toothpaste in children. The questionnaire included 
multiple-choice questions in which the respondents were instructed to choose only one appropriate response from a provided list of options.

\section{Results}

Responses of the study subjects on questions based on their knowledge and attitude regarding the use of fluoride toothpastes for children are tabulated in Table 1. Among the study subjects, $40 \%$ of the respondents considered that it is very important to brush child's teeth with fluoride toothpaste. Whereas $66 \%$ of them knew that atleast $1000 \mathrm{ppm}$ fluoride should be present in toothpaste for getting its benefit. $70 \%$ of the respondents recommended Kid's fluoride toothpaste for children and only $18 \%$ recommended regular fluoride toothpaste. About $45.3 \%$ were sure that kid's fluoride toothpaste has enough fluoride for getting its benefit whereas $13.6 \%$ do not think Kid's toothpaste have enough fluoride for its benefits. $20.3 \%$ of them think kid's toothpaste contains 1000 ppm fluoride. $60.7 \%$ knew about the symptoms seen when high amounts of fluoridated toothpaste were ingested. 52.3 $\%$ knew how to manage a child who had ingested high amounts of fluoride toothpaste. $64.7 \%$ knew how to reduce the intake of toothpaste by children. $66 \%$ of the dentists suggest brushing twice daily with fluoride toothpaste. $55 \%$ of them suggested pea sized toothpaste and $41 \%$ suggests smear sized/size of grain for children below 3 years.

The results of the study revealed that the knowledge and attitude among dental practitioners regarding the use of fluoride tooth paste for children was less.

Table 1: Multiple choice questions based on knowledge and attitude

\section{Multiple choice questions based on knowledge and} attitude Percentage

Do you think it is important to brush child's teeth with fluoride toothpaste?

\begin{tabular}{|l|c|}
\hline Yes, very important & $40 \%$ \\
\hline Yes, quite important & $45.4 \%$ \\
\hline Not important & $8.6 \%$ \\
\hline Do not know & $6 \%$ \\
\hline $\begin{array}{l}\text { Fluoride in toothpaste has which of the } \\
\text { following actions? }\end{array}$ \\
\hline Protects the tooth against demineralization & $5 \%$ \\
\hline Helps in remineralization & $6 \%$ \\
\hline $\begin{array}{l}\text { Makes the tooth more resistant to dental } \\
\text { caries }\end{array}$ & $19 \%$ \\
\hline All of the above & $70 \%$ \\
\hline
\end{tabular}

Which ingredient in toothpaste provides protection against dental caries?

\begin{tabular}{|l|l|}
\hline Calcium carbonate & $5.7 \%$ \\
\hline Sodium lauryl sulphate & $5.6 \%$ \\
\hline Sorbitol & $1.7 \%$ \\
\hline Sodium fluoride & $87 \%$ \\
\hline
\end{tabular}

How much fluoride should be present in toothpaste for getting its benefits?

\begin{tabular}{|l|c|}
\hline $5000 \mathrm{ppm}$ & $6 \%$ \\
\hline$>5000 \mathrm{ppm}$ & $6 \%$ \\
\hline $1000 \mathrm{ppm}$ & $66 \%$ \\
\hline $400-700 \mathrm{ppm}$ & $22 \%$ \\
\hline
\end{tabular}

Do you think kid's fluoride toothpaste have enough fluoride for getting its benefit?

\begin{tabular}{|l|l|}
\hline Very much sure & $14.4 \%$ \\
\hline Sure & $45.3 \%$ \\
\hline No & $13.6 \%$ \\
\hline Do not know & $26.7 \%$ \\
\hline
\end{tabular}

What type of toothpaste do you suggest for a child?

\begin{tabular}{|l|c|}
\hline Non Fluoride Toothpaste & $10.3 \%$ \\
\hline Fluoride Toothpaste & $18 \%$ \\
\hline Kid's Fluoride Toothpaste & $70 \%$ \\
\hline Ayurvedic Toothpaste & $1.7 \%$ \\
\hline
\end{tabular}

How much fluoride does kid's toothpaste contain?

\begin{tabular}{|l|l|}
\hline $1000 \mathrm{ppm}$ & $20.3 \%$ \\
\hline$>1000 \mathrm{ppm}$ & $18.7 \%$ \\
\hline$<500 \mathrm{ppm}$ & $33.7 \%$ \\
\hline $400-700 \mathrm{ppm}$ & $27.3 \%$ \\
\hline
\end{tabular}

If a child had ingested high amounts of fluoridated toothpaste, does it cause any of the following symptoms?

\begin{tabular}{|l|c|}
\hline Nausea, vomiting & $21.3 \%$ \\
\hline Abdominal pain, diarrhea & $17.7 \%$ \\
\hline Fall in blood pressure & $0.3 \%$ \\
\hline All of the above & $60.7 \%$ \\
\hline
\end{tabular}

How do you manage a child who had ingested high amounts of fluoride toothpaste?

\begin{tabular}{|l|c|}
\hline $\begin{array}{l}\text { Refer to the nearby } \\
\text { hospital }\end{array}$ & $16.66 \%$ \\
\hline Induce vomiting & $9.33 \%$ \\
\hline Give milk & $21.66 \%$ \\
\hline All of the above & $52.33 \%$ \\
\hline
\end{tabular}


Do you think any of the following methods can reduce the accidental ingestion of toothpaste by children?

\begin{tabular}{|l|c|}
\hline Parental supervision & $25 \%$ \\
\hline Use toothpastes with low fluoride & $2.7 \%$ \\
\hline Using the right amount of toothpaste & $7.7 \%$ \\
\hline All of the above & $64.7 \%$ \\
\hline
\end{tabular}

How many times do you suggest a child to brush their teeth per day?

\begin{tabular}{|l|c|}
\hline Once daily with fluoride toothpaste & $4.3 \%$ \\
\hline Twice daily with fluoride toothpaste & $66 \%$ \\
\hline Thrice daily with fluoride toothpaste & $0.3 \%$ \\
\hline $\begin{array}{l}\text { Once with fluoride toothpaste and once } \\
\text { with non fluoride toothpaste }\end{array}$ & $29.3 \%$ \\
\hline
\end{tabular}

\section{Discussion}

The use of fluoride toothpaste is the most costeffective fluoride homecare measure and there is strong evidence for a dose-response relationship. ${ }^{2}$ Many researchers have found that brushing with fluoride toothpaste reduces dental caries in schoolaged children but fluoride toothpaste use at an early age can be associated with dental fluorosis ${ }^{3}$. Younger children less than 3 years are likely to ingest toothpaste while brushing; this is the reason why many dental practitioners hesitate to prescribe fluoride toothpaste.

Although many studies are evaluating the efficacy of fluoridated toothpaste in children, still there is a lack of information within the dental community regarding the use, safety and efficacy of fluoridated toothpaste for younger children. Hence the present study evaluated the knowledge and attitude among dental practitioners regarding the use of fluoride toothpaste in children.

In this study, about $40 \%$ of them considered that it is very important to brush the child's teeth with fluoride toothpaste. $70 \%$ of the respondents knew about the protective action of fluoride on teeth against dental caries. A meta-analysis by Marinho et al 2 observed a significant reduction in caries with the use of fluoride toothpaste when compared with nonfluoride toothpaste or no toothpaste at all. A metaanalysis of eight clinical trials on caries increment in preschool children also showed that tooth brushing with fluoride toothpaste significantly reduces dental caries prevalence in the primary dentition ${ }^{3}$.

Researchers have shown that using fluoride toothpaste containing at least $1000 \mathrm{ppm}$ is essential for getting its benefit against dental caries. A review by Wong et $a l^{4}$ found evidence of a statistically
How much toothpaste do you suggest for a child who is less than 3 yrs?

\begin{tabular}{|l|c|}
\hline Pea sized & $55 \%$ \\
\hline Smear/ size of grain & $41 \%$ \\
\hline Toothpaste covering half of toothbrush head & $4 \%$ \\
\hline $\begin{array}{l}\text { Toothpaste covering the entire toothbrush } \\
\text { head }\end{array}$ & $0 \%$ \\
\hline
\end{tabular}

How much toothpaste do you suggest for a child who is more than 3 years of age?

\begin{tabular}{|l|c|}
\hline Smear/ size of grain & $19 \%$ \\
\hline Pea sized & $72 \%$ \\
\hline $\begin{array}{l}\text { Toothpaste covering the entire toothbrush } \\
\text { head }\end{array}$ & $8 \%$ \\
\hline Add toothpaste twice on the toothbrush. & $1 \%$ \\
\hline
\end{tabular}

significant benefit of using $1000 \mathrm{ppm}$ fluoride or more toothpaste relative to $250 \mathrm{ppm}$ fluoride toothpaste for caries prevention in the mixed/permanent dentition. Similar results were found in the other two reviews (Ammari et al ${ }^{5}$, 2003; Steiner et al ${ }^{6}, 2004$ ).In this study, $66 \%$ were aware that at least 1000 ppm fluoride should be present in toothpaste for getting its benefit, $70 \%$ of them suggested Kid's fluoride toothpaste which has less than $1000 \mathrm{ppm}$ fluoride whereas only $18 \%$ suggested regular fluoride toothpaste for children.

The commercially available Kid's fluoridated toothpaste contains less than $1000 \mathrm{ppm}$ of fluoride which is of less benefit for the teeth against dental caries. In this study, $20.3 \%$ of them thought that Kid's fluoridated toothpaste contained $1000 \mathrm{ppm}$ of fluoride. About $14.4 \%$ were very much sure that kid's toothpaste has enough fluoride for getting its benefit whereas only $13.6 \%$ did not think Kid's toothpaste has enough fluoride for its benefits. This shows the lack of knowledge among dental practitioners regarding the concentration of fluoride in Kid's toothpaste.

Nausea, vomiting, diarrhea, fall in blood pressure are some of the symptoms seen when fluoride toothpaste is ingested in high amounts. $60.7 \%$ of the respondents were aware of these symptoms.

In this study, $66 \%$ of the respondents in this study suggested twice daily brushing with fluoride toothpaste for children. To maximize the beneficial effect of fluoride in the toothpaste, AAPD suggests supervised tooth-brushing twice daily and rinsing after brushing should be kept to a minimum or eliminated altogether ${ }^{7}$. Parental supervision while tooth brushing, using toothpaste with low fluoride and using the right amount of toothpaste can reduce the incidence of 
Table 2: Recommendations on the use of Flouride toothpaste for children according to AAPD ${ }^{8}$ guidelines 20192020

\begin{tabular}{|c|c|c|c|}
\hline Age of the child & Amount of toothpaste & $\begin{array}{c}\text { Amount of fluoride } \\
\text { present }\end{array}$ & $\begin{array}{c}\text { Frequency of tooth } \\
\text { brushing }\end{array}$ \\
\hline Less than 3 years & $\begin{array}{c}\text { No more than Smear or } \\
\text { rice sized }(0.1 \mathrm{~g} \text { of } \\
\text { toothpaste })\end{array}$ & $0.1 \mathrm{mg}$ Fluoride & Twice daily brushing. \\
\hline 3-6 years & $\begin{array}{c}\text { No more than Pea- sized } \\
(0.25 \mathrm{~g} \text { of toothpaste })\end{array}$ & $0.25 \mathrm{mg}$ Fluoride & Twice daily brushing. \\
\hline
\end{tabular}

*To maximize the beneficial effect of fluoride in the toothpaste, AAPD suggests supervised tooth-brushing twice daily and rinsing after brushing should be kept to a minimum or eliminated altogether

fluoride toxicity in children. In this study, $64.7 \%$ of the respondents were aware of how to reduce the intake of toothpaste by children and $52.3 \%$ of them knew how to manage a child who had ingested high amounts of fluoridated toothpaste which shows moderate knowledge and attitude in this regard.

American Academy of Pediatric Dentistry (AAPD) latest guidelines ${ }^{8}$ recommendations are tabulated in Table 2. AAPD recommends using no more than a smear or rice-size amount of fluoridated toothpaste for children less than three years of age may decrease the risk of fluorosis. Using no more than a pea-size amount of fluoridated toothpaste is appropriate for children aged three to six ${ }^{9}$. The ADA currently advises to brush with water and to consult with a dentist or physician before using fluoride toothpaste, for children younger than 2 years. ADA Council recommends the use of smear of fluoride toothpaste (approximately 0.1 gram of toothpaste or 0.1 milligram of fluoride) from eruption of the first tooth to age 3 years followed by the use of pea-sized amount ( $0.25 \mathrm{~g}$ of toothpaste or $0.25 \mathrm{mg}$ fluoride) for children aged 3 to 6 years. This regimen is intended to maximize the caries preventive benefits of fluoride while further reducing the risk of developing fluorosis. The optimal dose of fluoride is $0.05 \mathrm{mg}$ per $\mathrm{kg}$ per day ${ }^{10}$. In this study, $55 \%$ of the respondents suggested pea-sized toothpaste and $41 \%$ suggested smear sized/size of grain for children below 3 years which shows a lack of knowledge among dental practitioners regarding the recommended amount of fluoride toothpaste for young children.

\section{Conclusion}

The use of fluoride toothpaste should be emphasized since fluoride is topically effective in preventing caries. In this study, dental practitioners have less knowledge and attitude mainly regarding the type of toothpaste and the amount of fluoride toothpaste to be prescribed for children. This study shows that dental practitioners lack knowledge regarding the use of fluoride toothpaste in children which needs appropriate steps to improve their knowledge by conducting dental health education. Better knowledge in this regard will enable dental practitioners to make appropriate decisions on the use of fluoride toothpaste in children.

\section{Source of funding}

None.

\section{Conflict of interest}

None

\section{References}

1. Glass RL. Caries reduction by a dentifrice containing sodium monofluorophosphate in a calcium carbonate base.Partial explanation for diminishing caries prevalence. Clin Prev Dent 1981;3(4):6-8.

2. Marinho VCC, Higgins JPT, Sheiham A, Logan S.Fluoride toothpastes for preventing dental caries in children and adolescents. Cochrane Database Syst Rev 2003;(1):CD002278.

3. Santos APP, Nadanovsky P, Oliveira BH. A systematic review and meta-analysis of the effects of fluoride toothpaste on the prevention of dental caries in the primary dentition of preschool children. Comm Dent Oral Epidemiol 2013;41(1):1-12.

4. Wong MC, Clarkson J, Glenny AM, Lo ECM, Marinho VCC, Tsang BWK et al, Cochrane Reviews on the Benefits/Risks of Fluoride toothpastes. J Dent Res 2011;90(5): 573-9.

5. Ammari AB, Bloch-Zupan A, Ashley PF. Systematic review of studies comparing the anti-caries efficacy of children's toothpaste containing $600 \mathrm{ppm}$ of fluoride or less with high fluoride toothpastes of $1,000 \mathrm{ppm}$ or above. Caries Res 2003;37(2):85-92.

6. Steiner M, Helfenstein U, Menghini G. Effect of $1000 \mathrm{ppm}$ relative to $250 \mathrm{ppm}$ fluoride toothpaste. A meta-analysis. Am J Dent 2004;17:85-88.

7. Scottish Intercollegiate Guideline Network, Dental interventions to prevent caries in children; March, 2014. Available from: "www.sign.ac.uk/assets/sign138.pdf".

8. American Academy of Pediatric Dentistry. The Reference Manual of Pediatric Dentistry 2019-2020:262-5. 
9. Wright JT, Hanson N, Ristic H, et al. Fluoride toothpaste efficacy and safety in children younger than 6 years. $J$ Am Dent Assoc 2014;145(2):182-189.

10. U.S. Institute of Medicine, Standing Committee on the Scientific Evaluation of Dietary Reference Intakes. Dietary Reference Intakes for Calcium, Phosphorus, Magnesium, Vitamin D, and Fluoride. Washington: National Academies Press; 1997.
How to cite: Aswathy RB, George S, Anandaraj S, Puthenpurackal VR, Haneef T. Knowledge and attitude among dental practitioners regarding the use of fluoride toothpaste for children. Int Dent J Student Res 2020;8(1):9-13. 